E3S Web of Conferences 2, 03001 (2014)

DOI: $10.1051 /$ e3sconf/20140203001

(C) Owned by the authors, published by EDP Sciences, 2014

\title{
Urban development and global sustainability
}

\author{
Fiorenzo Ferlaino \\ Istituto di Ricerche Economiche e Sociali del Piemonte (IRES), 10125 Torino, Italy
}

\begin{abstract}
In the 1950s, the economist Simon Kuznets theorized the existence of a bellshaped curve describing the correlation between the level of GDP per capita and income inequality. This generated another hypothesis concerning the existence of an inverted-U relationship between income per capita (GDP) and environmental impact. By means of a cross-country analysis, the article shows that, at least at the global scale, an Environmental Kuznets Curve (EKC) does not exist, but rather an Environmental Urban Curve (EUC). The city exhibits an complex socioeconomic metabolism that we can define in terms of dissipative and resilience territorial structures.
\end{abstract}

\section{Introduction}

The year 2008 has been characterized by four major events: the worldwide economic crisis, the consumption of farmed fish has exceeded the consumption of caught fish, the rate of growth of the world population has reached an inflection point(from now on, its growth will tend to decline in time); the world population has reached $50 \%$ of urbanization.

These epochal changes suggest that the crisis is something more than a depressive phase of the macro economic Shumpeterian cycle. The crisis started from its center (the U.S.) to spread over and take roots in Europe. In its peripheral areas, birth rates are declining and in many cases (both Western and Eastern Europe) they are insufficient for the reproduction of the next generation.

The ecological footprint is unsustainable for more than a decade and for several decades, the city has dominated the rural area : today the urban population in Europe has reached percentages of $70-80 \%$ of the total.

In Europe and Italy the traditional form of the historical city and the order of its distribution have been overtaken. From the market town, religious, administrative, military, with its beautiful palaces, forts, churches, craftsmen, who have made beautiful the "Belpaese", we have moved to the industrial cities that just around those centers are deployed. Nowadays, the historic centers are five to ten percent of the total residential space.

It has been exceeded even the industrial metropolis, result of the expansion of city and neighboring rural villages and characterized by the reproduction of the work with common spaces always insufficient and a urban rent "odd man out" between profits and salaries. The obsolescence of the central areas of the industrial city is literature and depends from the development and growth of the city, from its excessive flows inbound, from the increase of the value of land less than then profits, from the excessive stickiness accessibility of services and the difficult to move from the center to the periphery.

The compact city has grown again with the 'liberal city', the one who had created the drainage system, has widened the streets, made the boulevards and reorganized the internal urban structure. But after the 'social-democratic' city, the one of the low to the residence and services (last heritage of the industrial city) compact city it has been exceeded by serial districts, by terraced houses. Since then, the compact city doesn't exists and after the decline of industry is born as a new subject, difficult to define: the postindustrial-city. Around that it is difficult to identify a new engine of growth: perhaps the green economy, perhaps the "knowledge economy". Or, more likely, its long and creeping crisis. 
When the majority of people in the world is urbanized the ground on which stands the city and the metropolis it is not the agricultural and rural territory, but rather the opposite: the urbanized territory becomes the backdrop on which we can cut out natural, rural and agricultural areas.. This is what is happening in the world.

In this situation also changes the conception of environmental sustainability and it passes from Platonic model (still very very fashionable in the environmental culture milieu) to the more uncertain definition of the Brundtland Commission.

The Plato definition is clear: "the number of citizens can only be estimated satisfactorily in relation to the territory and the neighbouring states. The territory must be sufficient to maintain a certain number of inhabitants in a moderate way of live [...] and the number of citizens should be sufficient to defend themselves against the injustice. [...] The number of our citizens shall be 5040" (Plato, Dialogues, Laws, Book V).

On the contrary the Brundtland (1987) definition is not that clear cut : "Sustainable development is development that meets the needs of the present without compromising the ability of future generations to meet their own needs. It contains within it two key concepts: the concept of needs, in particular the essential needs of the world's poor, to which overriding priority should be given; and the idea of limitations imposed by the state of technology and social organization on the environment's ability to meet present and future needs."

But the first definition is relevant to a pre-industrial society only, the latter perhaps may provide a key to deal with the current situation of global environmental impacts.

\section{The world as a single city}

The post-industrial situation is characterized by the periurbanization, the sprawl, the rur-urbanization. They are representations, narratives of a unique dynamic which assumes specific morphologies of adaptation to physical places, to preexisting forms. In this "panorama" objects such as Megacities, Megapolis, linear City, Urban Sprawl, etc.. are the backdrop of human socio-economic activities. And this backdrop coexists with hierarchy and connectivity, competition and cooperation, anchoring and rooting, attractiveness and counter-urbanization, centripetal and centrifugal movements. But the most important characteristic is given by the radical change of these components in time, the acceleration of the change.

Compared to the traditional urban forms, the post-industrial city contains several objects that once again are difficult to define and therefore were summarily called "post-modern". We have shortlisted some of them:

1. the dual city contrasting the wealth to the poverty, the verticality of skyscrapers to the flatness of the slums made by low and spontaneous buildings straddling each other, the privatization of security of the middle and upper classes to the insecurity and danger of public spaces. It is Johannesburg, San Paulo, Bombay and the other cities of the third world.

2. the Hong Kong Style in which the rational knit of skyscrapers form a new compact city lattice, tidy and modern, emblem of a modernity perhaps already consumed;

3. the modern metropolis, which continues to exist especially in the Anglo-Saxon world, formed by the canonical trilogy form: the business center (the Central Business District, the American Downtown, the City of London), the residential compact zone and finally the urban sprawl formed by the rich villas and semi-detached houses;

4. The linear metropolis (along the coast, a major road or a river rod) that mimics the modern verticality around its nucleus, then follows a nasty suburbs which gives way to periurbanization along the road network, made up of a mix more (in the North) or less (in the South) functional, more or less orderly and monotonous;

5. the polycentric megalopolis where the Shanghai Style represents the most structured and recent framework: it is a global city on a modern background of residential nodes made by 
different metropolis, towns, villages mentioning and imitating historical places and forms, but also disclaims the sense of the time and of the space.

6. the city of decrease that, according to Serge Latouche, should be a city with a reduced carbon footprint, a strong relationship with the ecosystem and its bio-region, low consumption of resources, food, energy. Instead of megacities the city of decrease is an ecological city, made up of urban villages where cyclists and pedestrians using a renewable energy. From a political point of view the bioregion could be conceived as a city of the cities, municipaly within municipalities or perhaps a city created with villages, in other words a policentric or multipolar network.

These models, perhaps are too concise and certainly not exhaustive, it is however useful to open a debate on the future scenarios of the cities. In developed world areas it is absurd and paradoxical chasing the growth when the population is stagnant. It would be more appropriate to improve the present conditions and increase the distribution of our wealth. But it is very different in the case of the areas in developing countries where cities are growing rapidly. In general, it is impossible to think about a sustainable world that is the sum of small local sustainability, but it is also illogical to think that sustainability is not the total sum of the many regional sustainability, albeit with varying spatial scales.

\section{The city as a dissipative structure}

The modern metropolis can be conceived as a structure whose order is maintained through an energy dissipation which is far from its point of equilibrium (Prigogine., 1979; Prigogine, Allen, Herman, 1979). 1

The model to which this phenomenon can be easily compared is that of a thin layer of liquid in a tank heated uniformly from below: "When the heating is moderate, the liquid is in the second regime of linear non-equilibrium and the heat passes through the liquid by conduction. As the heating is intensified, however, at a well-defined temperature gradient, suddenly, the cells convention spontaneously occurs" (Prigogine, Allen, Herman, 1979, p.19). These dissipative structures, called "Bénard cells" (named after the physicist who discovered them, Henry Bénard), are hexagonal in shape and recall, although only for the planar pattern, the distribution equilibrium of markets as defined by Walter Christaller (1932). They give rise to an morphological order which is kept alive by a high energy dissipation around certain defined threshold values.

This is possible because of their nature as 'open systems' that can exchange both matter and energy with the environment: "The city as a dissipative structure receives inputs and high-quality resources from the outside, for example, from the sun, the surrounding countryside or the port-goods. These resources are transformed into components of the structure of the city or used to support the structure responsible for the organization of the city itself. Eventually, the degraded resources are discharged into the external environment [...] as waste consisting of matter or energy (entropy) "(E. Tiezzi, 1998, p. 85).

\footnotetext{
1 This hypothesis arose twenty years ago from the debate generated by the Nobel prize-winner Ilya Prigogine together with Peter M. Allen and Robert Herman (1979) in 'The Evolution of Complexity and the Laws of Nature. A Contribution to the $3^{\circ}$ Generation Report to the Club of Rome: Goals for a Global Society'. Dissipative structures are defined as particular organisations of matter and energy in open systems and are at the basis - from a physical and environmental perspective - of ordered systems and autopoietic systems (Maturana and Varela, 1985).
}

The environmental consequences of this thesis remain to be investigated, but the idea of the city as a social form of an energetic system is closely bound up with the city/natural resources and entropy/environment relationship (Georgescu-Roegen, 1971). 
In isolated systems, the exchange is denied, and neither matter nor energy can flow from the external environment. In closed systems, instead, there is exchange of energy, but not of matter, with the environment. The flow of energy and matter is what we denote with the term 'resources' not only in economics but also in ecology and physics. The amount of energy and matter extracted and processed also determines the various productive and connective organizations, and the networks that enable the exchange to take place. They therefore generate the specific social and economic structures.

Typically, only a small fraction of the flows of matter and energy which pass through an open system stop with that system; the rest flow to the external environment, resulting in a balance between inputs and outputs. Living systems, social organisms, geo-economic systems - that is, the set of 'autopoietic' systems - are systems that use the flows of matter and energy to maintain their internal order. Maintenance of the structure entails the qualitative degradation of the flows of matter and energy that, while maintaining the input and output quantities constant (in accordance with the first law of thermodynamics), change their type, their informative content, their structure and quality. Useful products and high quality energy are transformed into waste which must be regenerated or recycled.

There is a paradox which has been interestingly examined by Georgescu-Roegen in his seminal work (1971): the second law of thermodynamics, which states that systems tend towards "entropic death", is contradicted by the biological, social, economic and territorial systems that instead perpetually create a new order: new lives are constantly generated in the worlds of both plants and animals; new organizations, new cities, new organisms are created and spread.

The resolution of this apparent contradiction between the socio-biological and the physical worlds resides in "the fact that the second law of thermodynamics applies to systems near equilibrium" (HJ Morowitz, 1979), namely isolated (adiabatic) or isothermal systems. Human activity and organization of the territory do not belong to these classes; they are in fact systems far from thermodynamic equilibrium. It is possible to define them as "systems of systems".

Morowitz's diagram, i.e. a system inserted in a meta-system (the environment), describes the following situation. The environmental meta-system contains the energy sources and the discharge tanks/ of the other part of the intermediate system, which in this case is a city.

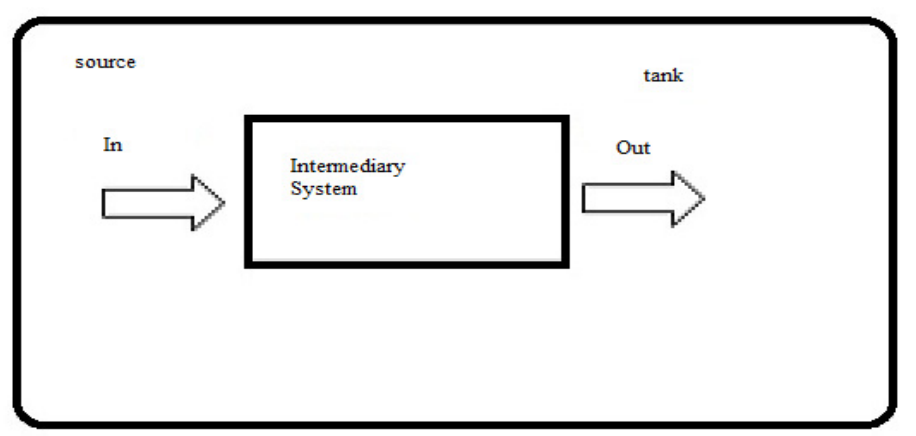

Figure 1. Morowitz's System.

The variation of entropy $\mathrm{S}$, at time $\mathrm{dt}$, which is denoted by $\mathrm{dS}$, is given by the formula:

$$
\mathrm{dS}=\mathrm{dSe}+\mathrm{dSi}>0
$$

where $\mathrm{dS}_{\mathrm{e}}$ is the entropy of the external system and $\mathrm{dS}_{\mathrm{i}}$ represents the entropy produced by the intermediate system (e.g. a city). The total entropy of the system will, because of the second law of thermodynamics, remain always positive: $\mathrm{dS}>0$, but this does not imply that the intermediate system 
must be entropic. The only restriction imposed by the second law of thermodynamics will be for (1) that: $\mathrm{d}_{\mathrm{e}} \mathrm{S}>-\mathrm{d}_{\mathrm{i}} \mathrm{S}$.

It is therefore possible to have negentropy and order in the intermediate system provided that $\mathrm{dSi}$ $<0$. In other words, "living organisms counteract the tendency of the universe to pass from order to disorder; they are able, that is to say, to create order in their organism while keeping it alive with their biological functioning, causing an increase in the disorder of their surrounding environment. The overall balance therefore respects the rule of entropy "(Bresso, 1993, p. 54).

Entropy in a dissipative structure (that is to say, a structure that dissipates the energy of the external system, the metasystem) may decrease (negentropy) if the intermediate system is traversed by large flows of energy. The city is a structure of this kind: it maintains its internal social order (i.e. its regulation) through the input of massive flows of energy (used for heating, transportation, creation and consumption of products, services, etc.)

If one considers the city as such, it is an energy-consuming organism characterized by a high level of consumption, a dissipative structure with very high internal organization. As Odum writes: "Money circulates in the economy among people but it does not pay for the processes and components to be found in the natural world (...) Within the human economy, flows of both energy and emergy converge on centres, which explains the occurrence of settlements and cities. "(Odum, 2005, p. 105).

Analyses conducted by IRES on the emergy accounting (Ferlaino and Tiezzi, 2001) or the ecological footprint (Bagliani M., F. Ferlaino, Martini F., 2005, Bagliani et al., 2012), of the city of Turin and the Piedmont region corroborate this hypothesis: the ecological footprint ${ }^{2}$ of Piedmont is 22,237,640 gha (global hectares), which is equal to 5.28 gha per capita. Its biocapacity (i.e. its usable ecological land in global hectares) is only 4,607,018 gha, so that its ecological deficit amounts to 17,630,622 gha, equal to 4.18 gha per capita. The province of Turin represents about $47 \%$ of Piedmont's total footprint of (Bagliani M., F. Ferlaino, S. Prokop, 2002) and it is estimated at 4 million gha, slightly less than the entire regional biocapacity. This means that a city as big as Turin would need the entire biocapacity of the Piedmont region to be sustainable. This figure can be considered very low if compared to Tokyo, which requires twice the area of Japan, or London, which requires twice the area of the biologically productive land of Great Britain, something as the whole of Spain. ${ }^{3}$

This significant energy dissipation (and its physical and operational transformation) is the cost to be paid for of a large town or city's welfare and structural complexity (which concerns both the organization and the decision-making process). Although there are considerable potential savings to be achieved from the higher productivity of matter and energy, as convincingly shown? by the Wuppertal Institut (von Weizsacker et al, 1998; Kuhndt, 2005), the morphology of the urban territory always needs a strong energy dissipation whereby the city can maintain its current levels of functional complexity. ${ }^{4}$

\section{The Environmental Kuznets Curve and the I-PAT Equation}

A city is a negentropic system. It is, therefore, a territory that requires high energy flows in order to

\footnotetext{
${ }^{2}$ Calculation of the Ecological Footprint has been recently modified by the Global Footprint Network. Consequently, there may be some (irrelevant) differences between the IRES calculations before and after 2007.

${ }^{3}$ Some of these figures are available at http://www.gdrc.org/uem/footprints/index.html.

${ }^{4}$ Functional complexity is a concept which is difficult to define and easy to understand. In extreme synthesis it can be seen as the possibility for each individual to play a social role and have a goal to pursue; thus being integrated and being an active agent within the social system (Parsons, 1951). The system becomes more complex when it absorbs the increase in the population (i.e. its components) into this process; on the contrary, it would tend to become simpler when it is not possible to integrate an increasing part of the population.
} 
maintain its internal order. These flows may or may not be sustainable. They are sustainable if they fulfil the following criteria defined by the economist Herman Daly (Daly, 1981):

the principle of sustainable efficiency: the resources must be consumed at a rate that allows the environmental system to restore them.

and the principle of absorptive capacity: the production of goods must not generate wastes, discards and pollutants that cannot be absorbed by the system in a reasonably short time; there must be no cumulative effects.

The entire metabolic system, in extreme synthesis, is simply the transformation of (physical) natural capital (especially the materials collected in the primary and mining sector) through the use (a particular organization) of energy (derived from both human labour and machinery). The transformation of matter without form into matter that has a form which is connected to its function and utility? is clearly a negentropic action that needs, as we have seen, a high energy flow. The cycle of transformation of natural capital must respect Daly's principles of if it is to be sustainable over time. The cycle is in equilibrium if the speed of the phase of consumption [of the resources] is equal to the speed of the phase of regeneration. If the law of equality between consumption and regeneration is not observed, there is an accumulation of waste that will impact on the glocal territory.

This balance is not respected today. Since the mid-1980s, the Earth has not regenerated the consumption of natural capital (in particular the excessive production of $\mathrm{CO} 2$ ), and this unsustainability continues to increase. The day on which the Earth's biocapacity reaches the amount of natural capital consumed during the year is called Earth Overshoot Day ${ }^{5}$, and, in 2011, it was conventionally established as the $27^{\text {th }}$ of September. From September 28 to December 31, the wastes produced are not absorbed, so that they impact on the global territory and change the balance of the ecosystem. What must be done in order to restore sustainability?

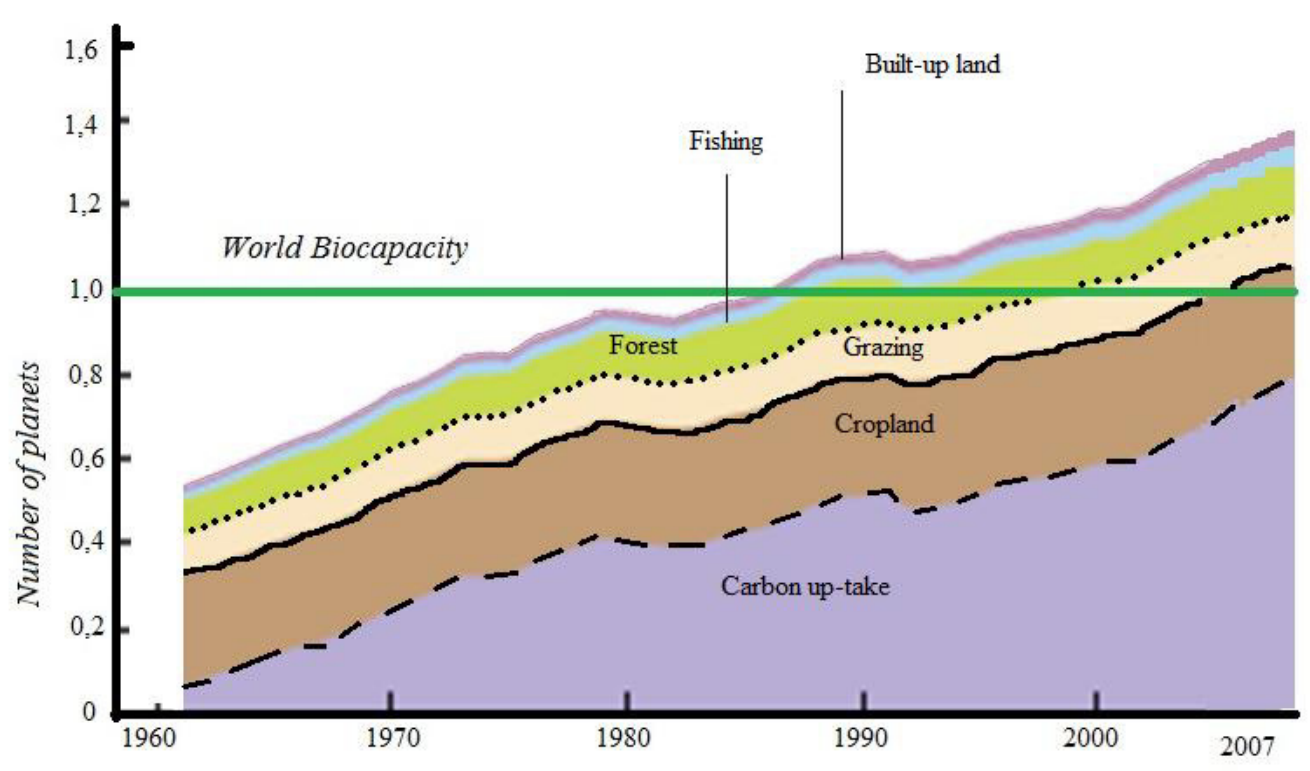

Figure 2. Ecological Footprint broken down into its various components (1961-2005)

Source: author's elaboration on WWF, 2010

\footnotetext{
${ }^{5}$ L'Earth Overshoot Day has been defined as "the day of the year in which human demand on the biosphere exceeds what it can regenerate". See http://www.footprintnetwork.org/it/index.php/gfn/page/earth_overshoot_day/
} 
A positive and liberal response to the question of sustainability is given by the proponents of the Environmental Kuznets Curve '(EKC). According to these theorists, economic growth drives an increase in the environmental impact until a certain threshold (the turning point) and a decrease in this variable at a second stage. This curve is inverted U-shaped and scholars are currently debating as to whether it is possible to identify Kuznets? curves in relation to environmental consumptions, and for what reasons. Other scholars have suggested different strategies: the "zero growth" economy (Meadows, 1974) or, more recently, " happy degrowth" (Latouche, 2007). The question is therefore posed in terms of 'growth', 'zero growth' or 'degrowth'.

The I-PAT equation of Ehrlich and Holdren (1971), however, makes scenarios of 'zero growth' and 'degrowth' (at least a "happy degrowth") rather unlikely, especially at the global scale, because one of the factors - the population - will continue to increase in the medium and long term. The equation expresses the total impact as a multiplicative effect of the population (stock), of the measurement of consumptions (behaviours), and of the present state of technology (environmental efficiency of production).

$$
\text { Impact (I )= Population (P) x Affluence (A) Technology (T) }
$$

where:

$\mathrm{A}=$ consumption per capita $(\mathrm{C} / \mathrm{P})$

$\mathrm{T}=$ the impact per unit of consumption $(\mathrm{I} / \mathrm{C})$

In quantitative terms, the formula becomes:

$$
I=P \cdot \frac{C}{P} \cdot \frac{I}{C}
$$

Which is equivalent to:

$$
I=P \cdot \frac{P I L}{P} \cdot \frac{I}{P I L}
$$

Both the first factor, the population (P), and the second factor, the amount of consumption ((GDP per capita), are growing, while there is a large body literature that questions the Kuznets hypothesis and the trade-off between environmental impact (I) and wealth (GDP) in mature economies. This debate focuses on the third factor of the I-PAT Equation: the possible decrease in the impact of technology within mature local systems and, therefore, the relative increase in productivity per unit of energy and matter consumed. The increase in energy productivity together with the growing dematerialization of goods would lead to the 'natural' detachment (delinking or decoupling) of GDP growth from the growth of natural capital consumption. 


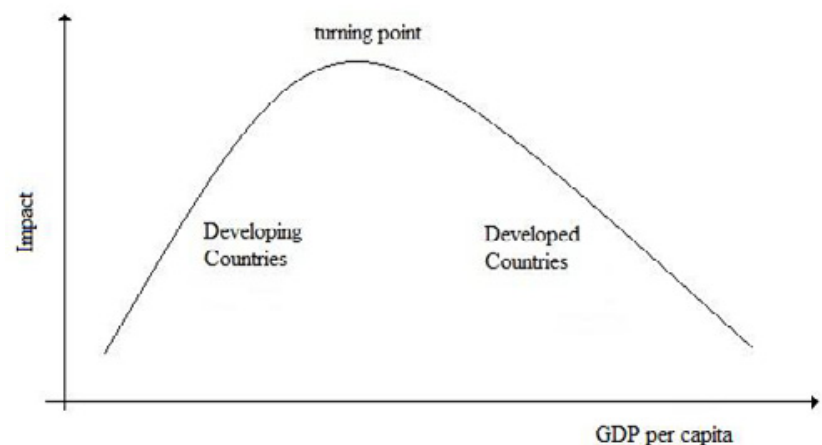

Figure 3. The environmental Kuznets curve

The issue of 'delinking' is a matter of debate (Mazzanti, Zoboli, 2005, Singer 2010). It centres around demonstration of the theoretical hypothesis that the impact of technology grows at low levels of GDP, then reaches a peak, inverts the curve, and begins to decrease in conjunction with higher levels of wealth.

\section{I-PAT Equation and cities}

What is underestimated by current theories is a territorial view of the effects which, as will be demonstrated, have implications different from those commonly set out in the literature. A different hypothesis regarding the EK-curves can be formulated. It refers to the urban environment, seen as an adaptive morphology that responds to both economic purposes (the increase in consumption per capita) and environmental purposes (reducing per capita energy consumption). The classical formulation of the EK-Curve is, in fact, the result of a false cause and a false correlation.

In order to demonstrate this, it is necessary to consider the I-PAT equation (3) and briefly analyse each of the members, Population (P), Affluence (GDP/P) and Technology (I/GDP), bearing in mind that the equation should be understood from a qualitative rather than quantitative perspective because the various terms (Population, Affluence and Technology) are not independent but interact through dynamics based on the central role of cities in the process of consumption and production.

It is well known that the global population (the first term) grew exponentially until the beginning of the new century and now - presumably following the trend of a logistic equation (Fig. 4) - tends to move towards a new carrying capacity, an asymptote, and a new balance. It is still difficult to determine this new equilibrium quantitatively, but the UN hypotheses suggest a scenario of a minimum of 7.9 billion inhabitants in 2050 and a maximum of 10.46 billion (UN, 2009), while the inflection point? of the logistic equation seems to have been reached only a few years ago. However "the end of the twentieth century is marked by a demographic slowdown that suggests the possibility of stabilizing the world population" (Véron, 2009, p.513). In fact, stabilization of the population is a strong assumption and, as the theory of systems shows, the process may tend towards an asymptote, as well as fluctuating in time and/or being subject to a sudden "catastrophic fall" (Thom, 1980). What happened on Easter Island is a warning to be heeded in this regard (Diamond, 2005). ${ }^{6}$

\footnotetext{
${ }^{6}$ The reference is to the Rapa-Nui civilisation of Easter Island, whose inhabitants Captain Cook already described in 1774 as "minute, emaciated, shy and unhappy" due to the destruction of environmental resources (woods and agriculture). They numbered 7000 in the sixteenth century and had grown to 1500 by the beginning of the nineteenth century. This demographic increase required a profound change of the social, cultural and organisational structure which took the form of continuous
} 
Assuming that the most optimistic scenario (the stabilization of the population) will come about, it is still necessary to examine the compatibility of this 'new balance' with the environmental resources because, according to the results of the Living Planet Report (WWF, 2010), the consumption of natural capital (ecological footprint) doubled from 1961 to 2005 and is about 30\% higher than what the planet can regenerate in a year.

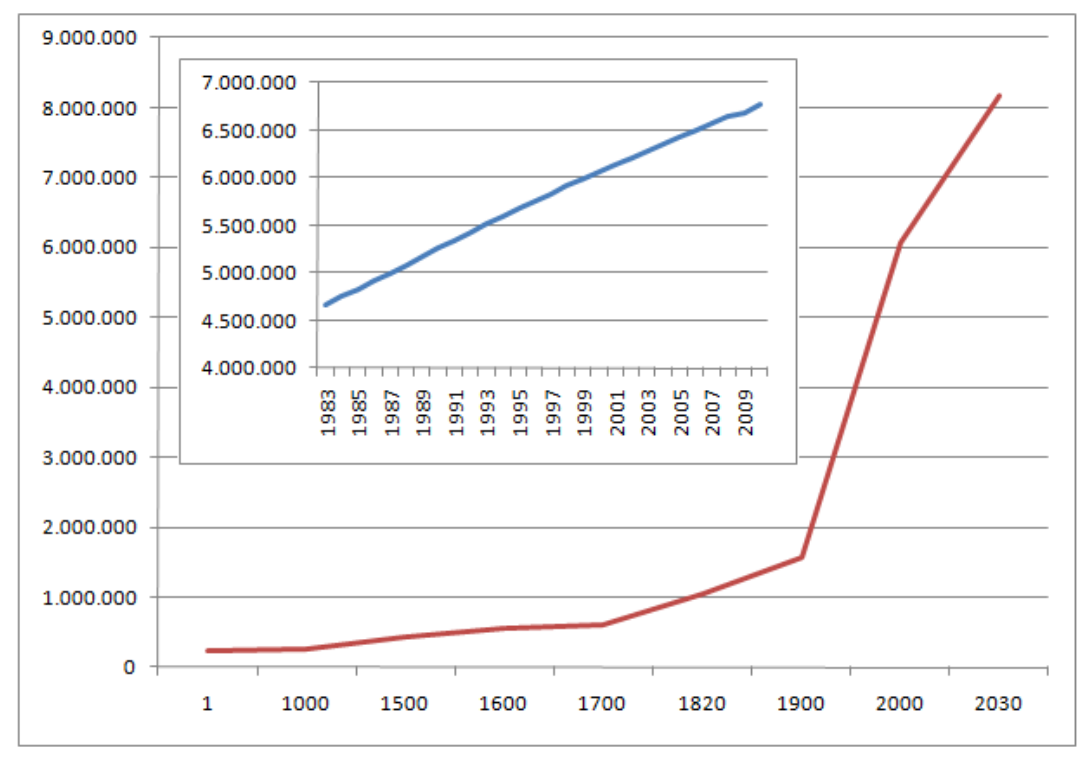

Figure 4. The growth of the world population

Source: IRES calculations on J. de Vries tables 3.2, 3.6, 3.7and on OECD data

The Population (P) factor is certainly the main source of environmental impact, and it is also the factor most difficult to change in the short term. Furthermore, many economists regard the decrease of this factor as a catastrophe because it may lead to destabilizing scenarios in the economic and social structure.

The economic importance of this factor is apparent if we compare its growth with that of the second factor, GDP/P. On considering the data since 1950, when both the population and GDP per capita worldwide had a value of 100 , it is interesting to note that while the former has had a quasi-linear trend in recent years, the latter, Affluence (consumption), has a trend which is more than proportional (Fig. 5).

wars and tensions that degenerated into cannibalism and infanticide (Diamond, 2005). In this case that of a closed system - Malthus was right. 


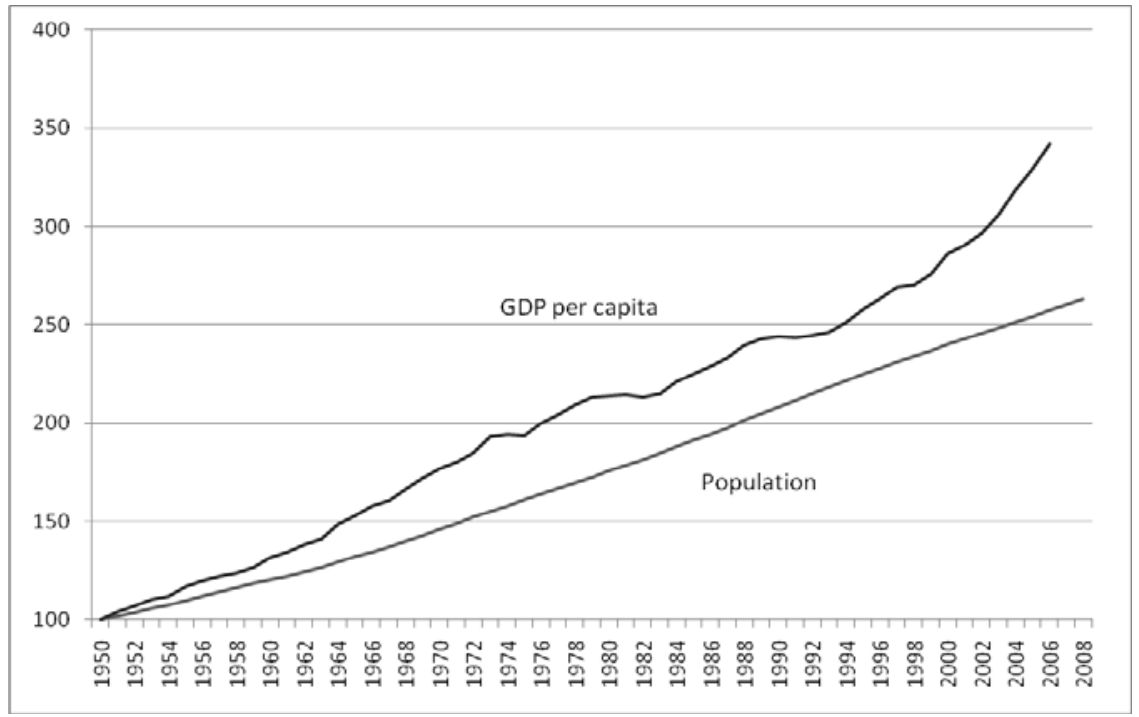

Figure 5. The relationship between population growth and gross domestic product (average) in the world $(1950=100)$

Source: Historical Statistics of the World Economy: 1-2008 AD (A.Maddison), 2010 elaborated by IRES.

The role of cities in population growth has been much debated. The literature has highlighted the correlation among industrial growth, population growth and urban development. This relationship, however, has become rather complex in the post-industrial and knowledge society. On considering relatively large territories ${ }^{7}$ (we considered in our study only states with more than 5 million inhabitants) and using a synchronic cross-country analysis, some paths of development can be traced which, although different, can all be ascribed to some stable macro-dynamics of growth.

1. To be noted is the indubitable correlation between urbanization and wealth. The latter (Fig. 6) increases more than proportionally with the consolidation of the urban model that seemingly leads to some kind of economic take-off, thereby confirming the findings of many analyses.

\footnotetext{
${ }^{7}$ Figures on GDP, energy consumption, fertility rates, and population have been taken from CIA World Factbook (2009) (https://www.cia.gov/library/publications/the-worldfactbook/rankorder/rankorderguide.html), while the historical series on population and the percentages of urbanisation have been taken from Historical Statistics of the World Economy: 1-2008 AD (A.Maddison) and from the United Nations' 'World Urbanization Prospects: The 2007 Revision Population Database'. Only countries with more than five million inhabitants and without omissions in their databases (i.e. with complete demographic and economic data) have been considered. Arab Emirates have been excluded because their per capita energy consumption is anomalous with respect to that of the other countries. Overall, 109 countries out of 237 on which data are available have been considered. They are: Afghanistan, Algeria, Angola, Argentina, Australia, Austria, Azerbaijan, Bangladesh, Belarus, Belgium, Benin, Bolivia, Brazil, Bulgaria, Burkina Faso, Cambodia, Cameroon, Canada, Chad, Chile, China, Colombia, Congo (Dem Rep), Cote d'Ivoire, Cuba, Czech Republic, Denmark, Dominican Republic, Ecuador, Egypt, El Salvador, Eritrea, Ethiopia, Finland, France, Germany, Ghana, Great Britain \& Northern Ireland, Greece, Guatemala, Guinea, Haiti, Honduras, Hong Kong, Hungary, India, Indonesia, Iran, Iraq, Israel, Italy, Japan, Jordan, Kazakhstan, Kenya, Korea (North), Korea (South), Kyrgyzstan, Laos, Libya, Madagascar, Malawi, Malaysia, Mali, Mexico, Mongolia, Morocco, Mozambique, Myanmar, Nepal, Netherlands, Nicaragua, Niger, Nigeria, Pakistan, Papua New Guinea, Paraguay, Peru, Philippines, Poland, Portugal, Romania, Russia, Rwanda, Saudi Arabia, Senegal, Slovakia, Somalia, South Africa, Spain, Sri Lanka, Sudan, Sweden, Switzerland, Syria, Tajikistan, Tanzania, Israel, Togo, Tunisia, Turkey, Uganda, Ukraine, United States of America, Uzbekistan, Venezuela, Vietnam, Yemen, Zambia, Zimbabwe.
} 


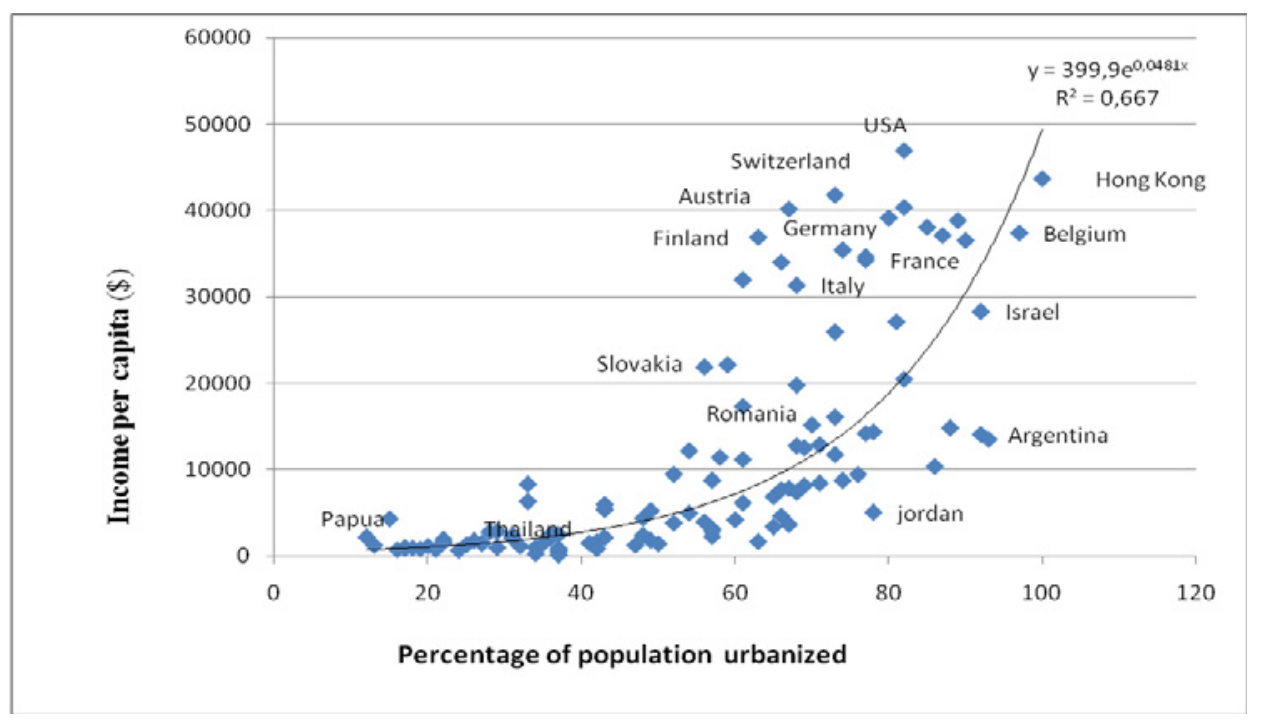

Figure 6. Correlation between GDP per capita and percentage of urban population (year 2009) Source: IRES calculations on CIA 2009 data

When urbanization increases, wealth grows more than proportionally: the city seems to be an organization that improves economic welfare by shifting and concentrating resources. The agglomeration and densification of the territory is a form of economic optimization because it tends to maximize the welfare of both producers and consumers (Launhardt, 1885, Rosen and Resnick, 1980).

2.The modern city is a demographic 'black hole'. Its growth can be entirely attributed to the strong attraction that it exerts on the surrounding areas, and to the rural/urban migration that converges on the city as a source of prosperity. The population explosion of the past two centuries, in fact, has depended on the complex relationship between the existence of urban industrial and post-industrial centres and the generative capacity of the rural systems that they attract (a form of resistance developed by the recessive mode of production); systems that have passed from the regional and local dimension to more extensive national, and now, international ones.

If fertility rates are correlated with the rate of urbanization, this relationship is evident and shows the 'black hole' effect of the birthrate (Fig. 7): the city attracts people from non-urban areas by offering a certain degree of welfare (in terms of wealth and longer life expectancy) but in return limits their capacity for self-reproduction?. 


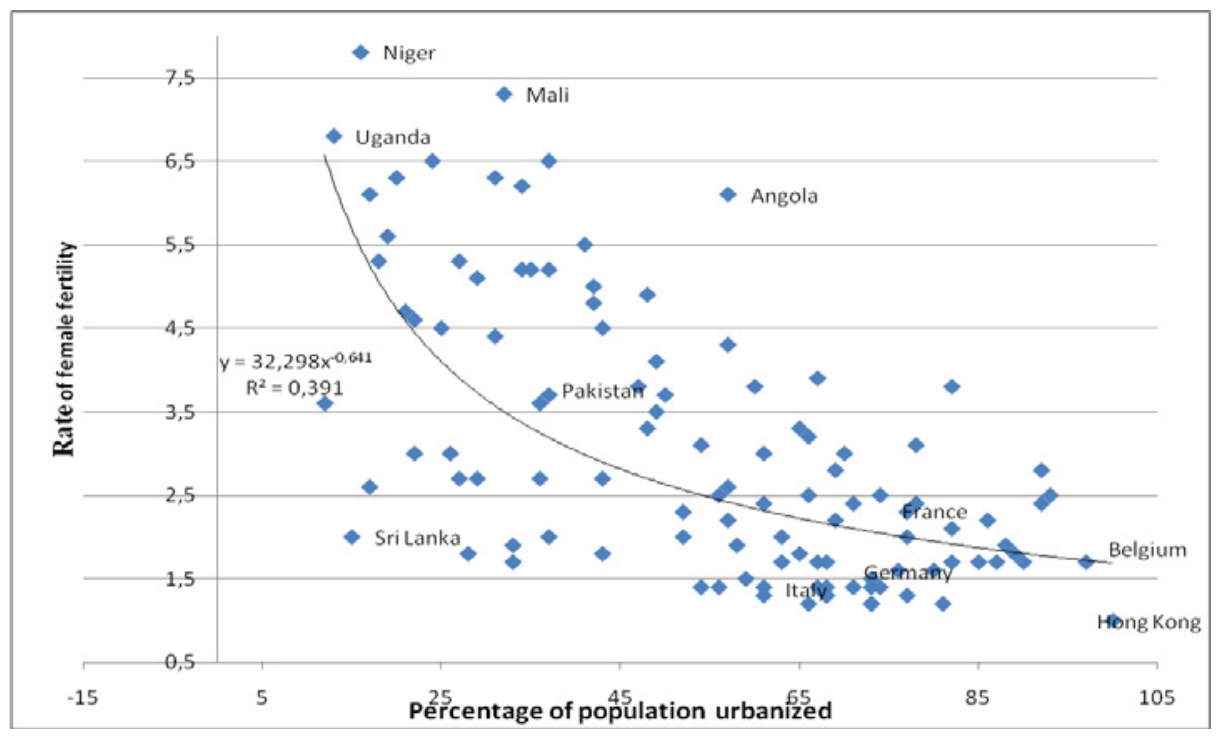

Figure 7. Relationship between the fertility rate and the percentage of urban population (2009) Source: IRES calculations on CIA, 2009 data

It is interesting to note that the more urbanization increases, the more reproductive behaviours become homogeneous. The evolutionary paths of differentiation decrease with urbanization, and in the metropolises, the territories-cities (those with $90-100 \%$ urbanization rates), and megacities, fertility rates are very low.

In the post-industrial metropolis, these behaviours seem to generate a demographic dynamic that most likely tends towards a new Malthusian equilibrium. This is made possible by a process which on the one hand curbs increasing global birth rates and, on the other, defines a new threshold for the quality of life. All this comes about primarily through the imposition/choice of new reproductive behaviours generated by a set of concomitant causes all related to the urban lifestyle: strong competition for access to resources, steady productivity growth, but also increasing life expectancy, greater needs and possibilities to change activities and roles, greater opportunities for consumption, etc.

3.The third factor is Technology. A significant 'proxy' is used to evaluate its impact: namely the energy consumption as defined by the standardized sum of oil, gas and electrical consumption. ${ }^{8}$ It is interesting to note that energy consumption ${ }^{9}$ is strongly (linearly) correlated with the GDP ( $r$-squared $=0.84$ ), which would seem to contradict or undermine the hypothesis of the EKC at the global scale.

\footnotetext{
${ }^{8}$ Consumptions have been standardised in Kilocalories $\left(1 \mathrm{Kcal}_{\mathrm{th}}=4,186 \mathrm{~J}\right)$. The assumption behind this indicator is that the impact generated by a thermic calorie is the same for the different sources of energy (gas,oil, electricity). This is corroborated by the fact that $1 \mathrm{mc}$ of gas (which has less impact than oil) is equivalent to $9500 \mathrm{kcal}$, while a litre of oil is equivalent to $11.000 \mathrm{kcal}$. Moreover, as regards electric energy and without considering nuclear energy, only $17 \%$ of global electricity is produced from this source, while 39\% derives from carbon, and around $20 \%$ from hydroelectric and renewable energies.

${ }^{9}$ Arab Emirates have not been considered because their per capita energy consumption is anomalous with respect to to the other countries.
} 


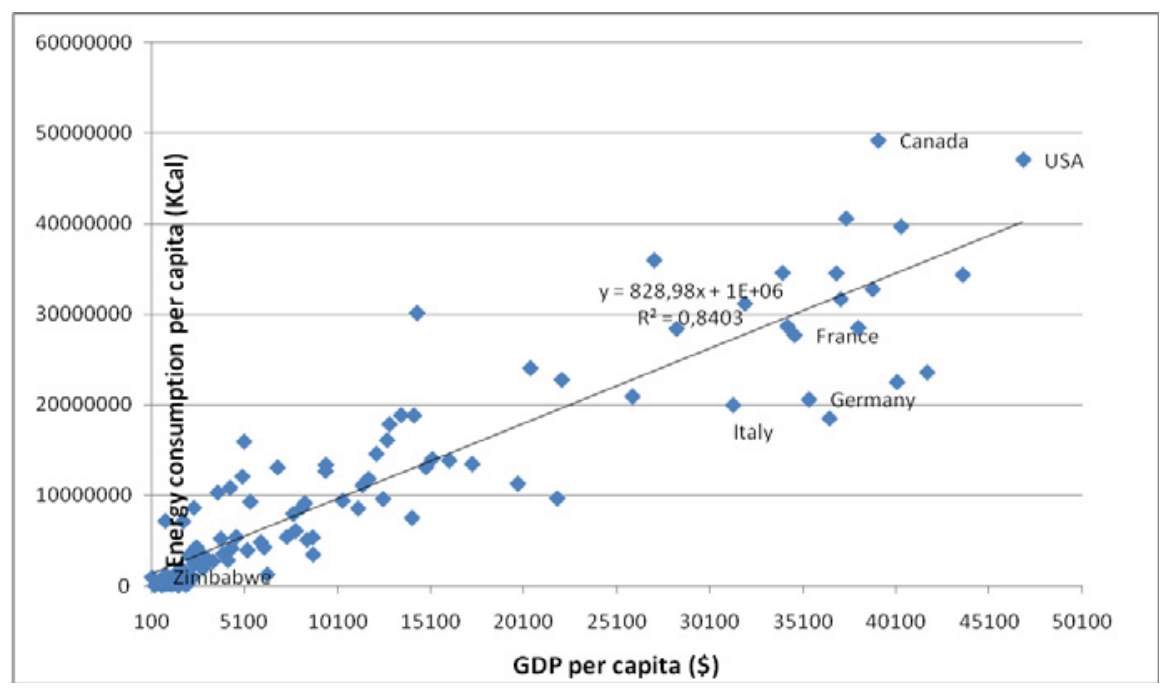

Figure 8. GDP per capita and energy consumption per capita (2009)

Source: IRES calculations on CIA, 2009; WBM, 2009 data

It should also be noted that the distribution of countries is characterized by a strong concentration towards the bottom (where the great majority of the poor countries are located) and upwards (developed countries), while the intermediate values are more rarefied. From this It follows that the growth process tends to be dichotomous, as the numerous analyses of unbalanced development on an international scale seem to have proved.

If energy consumption per unit of GDP is instead correlated with urbanization, the intercept polynomial shows a complex relationship tending to assume an inverted U-shape (a parabola, Fig. 9). The interpretation of this relation seems to suggest that the city plays a dual role: the growth of urbanization causes an increase in the impact generated, but above a certain threshold (about $60 \%$ of the urban population) it tends to decrease, reaching a much lower intensity.

Energy consumption should therefore be related to two different kinds of process: the city acts at a first stage as an accelerator of the impact, thereby generating 'growth' ${ }^{10}$ and, at a second stage, that of mature local systems, when urbanization has surpassed a certain threshold (over $60 \%-70 \%$ of the urban population) it creates 'development' - that is, implementing? the well-being of the population and, at the same time, reducing the impacts (in relative terms, per person). A particular form of ' territorial delinking' takes place and decouples the urban growth from the environmental impact generated.

This process is not a canonical EKC. indeed, it is not defined as a reduction of the environmental burden correlated with an increase in GDP (which grows proportionately as shown by the crosscountry analysis). Rather, it is correlated with a particular form of social organization, namely the urban organization. The cause of this trend does not depend on the technology used (as we have seen, energy consumptions increase with wealth) but on the introduction of economies of scale that occur when the social concentration becomes greater and exceeds certain thresholds. It is of interest to examine some aspects of these relationships:

a. The intercept polynomial of second degree takes the shape of an inverted U;

b. Besides developed countries (USA, Germany, France, UK, etc..) and the most efficient ones (Netherlands, Sweden, etc.), other nations can be found in the upper section of the graph, namely:

10 'Growth' should be understood as the improvement of economic well-being at the expense of the environment (Tiezzi, Marchettini, 1999). 
some countries with lower incomes but with strong rates of urban population indices in developing countries (Venezuela, Argentina, Cuba, Brazil, Jordan); Eastern European countries (Czech Republic, Romania, Bulgaria); and, finally, city states like Hong Kong;

c. The trend does not show a dichotomous distribution of countries but rather a diffuse one.

This fact can be interpreted as a particular state of 'territorial delinking ' (Ferlaino and Lami, p.91) generated by the urban organization.

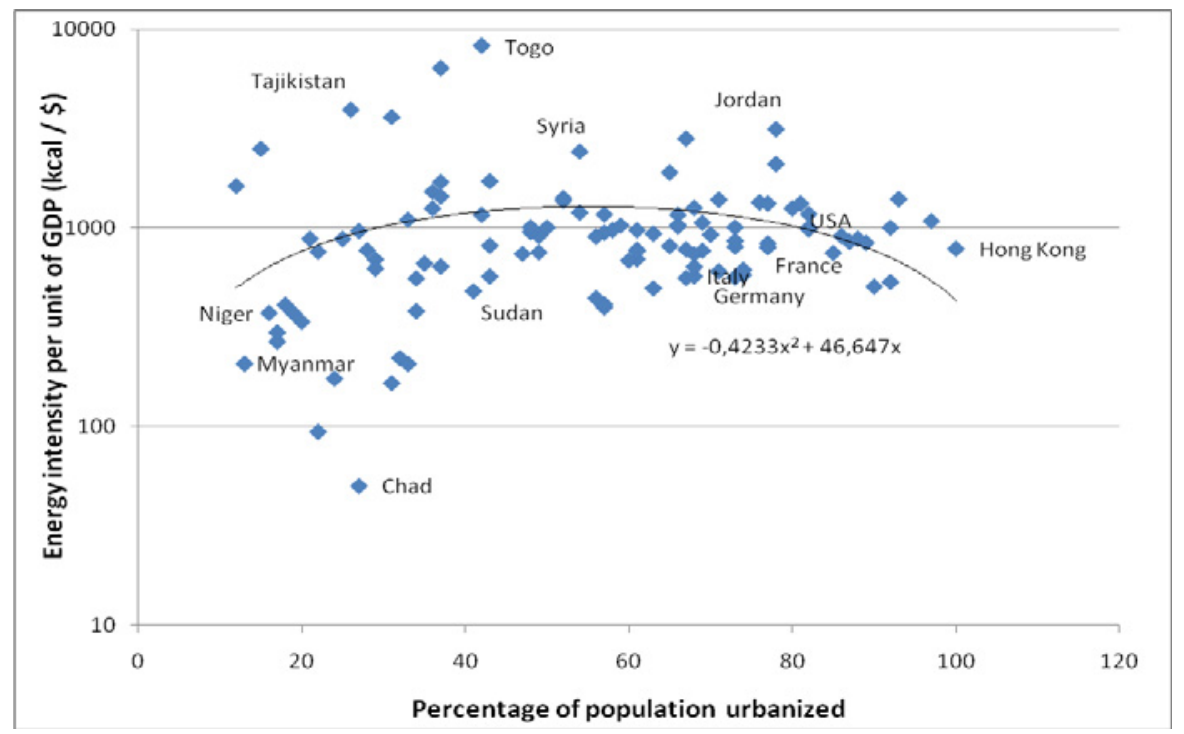

Figure 9. Relationship between the impact generated by a unit of GDP produced and the \% of urban population (2009)

Source: IRES calculations on CIA, 2009; WBM, 2009 data

At the local level, the terms of the debate appear to be consistent with this finding and highlight the role that the metropolitan and urban organization plays in mature systems.

Piedmont (the region in which I work) can be considered a representative example. Emergy per person, or the energy embodied and imported from the city of Turin in one year (measured in joules) was, according to our data (Ferlaino, Tiezzi, 2001), half of the regional amount and lower than national one. The same result is obtained when evaluating the ecological footprint per person in the province of Turin. Again in the same year, it was lower not only in comparison with the regional amount but also in relation to the emergy of the other provinces, with the exception of VerbanoCusio-Ossola (the lowest among the provinces of Piedmont).

Can these results be generalized? It would seem so. in 2001 Liverpool had a EF (Ecological Footprint) of $4.15 \mathrm{gha} / \mathrm{cap}$, compared with an average of $4.9 \mathrm{gha} /$ cap in Great Britain (Barrett and Scott, 2001), In 2000 Berlin had an ecological footprint of 4.06 gha/cap against 4.7 gha/cap in Germany (Pacholsky, 2000), and in Scotland, where a very detailed analysis was carried out, five out of the six 
cities considered had footprints below the national average ${ }^{11}$ (Chambers, Griffiths, Lewis, Jenkin, 2004). ${ }^{12}$

Hence there is a differential between poorly and highly urbanized nations which places the latter within more efficient processes of matter and energy production, probably dictated by the more effective local organization and by the more efficient use of economies of scale. In other words, the urban organisation is certainly not irrelevant?: it seems clear that dispersion generates strong negative externalities, incomparably higher collective costs (Camagni, Gibelli, Rigamonti, 2002), and a higher per capita ecological footprint (Høyer, Golden, 2003) .

\section{Concluding remarks}

Is it possible to achieve a new ecological balance without reducing the socio-economic complexity that distinguishes advanced societies? Can it be attained without the endogenous simplification of complexity brought about by social conflicts and wars to hoard limited resources, the reduction of freedoms and of collective services, or the simplifications imposed by exogenous environmental change such as the catastrophic reduction of natural resources? The data from the environmental accounting of the Western economies show that the unavoidable and urgent issue for the current growth model of is rapid and programmed abandonment of the energy produced by fossil fuels. As Figure 2 shows, the absorption of carbon emissions occupies half of the global ecological footprint. ${ }^{13}$ The city, or rather the compact network of nodes (exactly the opposite of the peri-urban and rururban sprawl and of the diffused city, etc..), can play an important role in a new green (or blue, as some have suggested) economic scenario. ${ }^{14}$

a. In 2009 , for the first time in human history, the urban population exceeded the rural one. The urban morphology is therefore the culmination of a process that tends to structure and complexify the world, the entire territory, and still for a few decades respond to the increase of the global population. The requirement for that epigenesis is, as this article has sought to show, that functional and social complexity be based on the cities as dissipative and resilience systems: that is, ordered systems far from thermodynamic equilibrium and with high 'internal functional organization'. These organisms, the cities, are by definition energyintensive systems. Complexity and order, in a process of further growth of the world population, do not require less (as many seem to believe) energy but more. The urgency of overcoming dependence on fossil fuels is thus heightened.

b. The morphological organization of the population plays a central role in this process. This organization transforms the metabolism of demographic and social processes which modify reproductive forms through the collapse of fertility rates and the emergence of (economic and cultural) behaviours that tend to reduce the P-factor of the I-PAT Equation. This is a resilience factor.

\footnotetext{
${ }^{11}$ Edinburgh 5.12 gha/ab., Dundee 5.04, Inverness 5.00, Glasgow 4.91, Angus 4.78, compared with an EF (ecological footprint) di 5.35 gha/cap?. for Scotland. Only Aberdeen (5.37) had a footprintabove the national average. Other sources have measured London's EF as equal to the national average, excluding the percentage due to tourists.

${ }^{12}$ These values are even more important considering that the ecological footprint is measured more on the basis of consumptions (and of the biocapacity necessary to regenerate them) than on the basis of productive flows.

${ }^{13} \mathrm{CO}_{2}$ emissions are the major cause of climate change and of the most dangerous transformative processes. In this sense, the balance calculated by this study confirms the environmental unsustainability of the city of Turin (Ferlaino and Tiezzi, 2001) : the overall calculated (in 1998) value is $7,04 \times 10^{6}$ tons while the amount of $\mathrm{CO}_{2}$ fixed per year according to the vegetation present in the area of Turin is $2,43 \times 10^{4}$ tons. The entire region of Piedmont (without any other comunality) would be necessary to make the city of Turin sustainable, while the entire natuaral capital available in northen Italy would be needed for the sustainability of the entire population of Piedmont.
}

14 As argued by Gunter Pauly in Blue Economy (2010), the 'blue economy' is a particular part of the green economy that aims to imitate nature through biomimesis and reduce economic investments. 
c. The social space, especially in developing countries, continues to converge towards the urban nodes, as ordered and complex places which can offer prosperity and, consequently, high life expectancy. An important role for the new balance and distribution of the network and poles will be played by the increase in oil prices, which constitutes the real device (far more effective than planning rules) with which to reduce sprawl and generate strong centripetal forces.

d. At the same time, in mature cities the trade-off between the rate of urbanization and energy consumptions per capita define forms of savings, optimization, and economical use of resources. After an initial growth necessary for the urban take-off, at high rates of urbanization, a decrease in the intensity of energy consumption occurs. This is another resilience factor. The hypothesis that this article has tried to demonstrate is that it is the urban organisation in its maturity which generates significant economies of scale and mechanisms that render the dynamics of flows more efficient, through the Urban Environmental curves.

These are mechanisms of transformation that if, on the one hand, exclude a return to the 'small and beautiful' (except as further urban sprawl and dissemination of the city in polycentric form) and the connection (if not symbolic) to the local pre-industrial forms of organisation, on the other hand, do not guarantee a plain diffusion model of the urban-metropolitan network and the implementation of levels of social complexity. It seems to spread in the global space a resilient organizational forms (environmental resilience) that maintain social and economic complexity only through a large energy dissipation. This requires a sudden transition from fossil fuels to renewable energy. There is no time for anything else. 


\section{References}

1. M. Bagliani, M Battaglia., F. Ferlaino, E. Guarino, Atlante della contabilità ambientale del Piemonte. Geografia e metabolismo dell'impronta ecologica (IRES, Torino, 2012)

2 M. Bagliani, F. Ferlaino, F. Martini, Contabilità ambientale e impronta ecologica: casi studio del Piemonte, Svizzera e Rhône-Alpes/ Ecological Footprint Environmental Account: study cases of Piedomnt, Switzerland and Rhône-Alpes (IRES, Torino, 2005)

3. M. Bagliani, F. Ferlaino, S. Procopio, L'Impronta Ecologica, Rapporto sullo stato dell'ambiente 2002 (Arpa-Piemonte, Torino, 2002)

4. J.Barret, A. Scott, An Ecological Footprint of Liverpool: Developing Sustainable Scenarios. A detailed Examination of Ecological Sustainability (Stockholm Environment Institute and Sustainable Steps Consultant, Stockholm, 2001)

5. M. Bresso, Per una'economia ecologica (La Nuova Italia Scientifica, Roma, 1993)

6. Brundtland Commission Report, World Commission on Environment and development, Our Common Future (Earthscan Pub, London,1987)

7. R.Camagni, M.C.Gibelli, P.Rigamonti, I costi collettivi della città dispersa (Alinea ed, Firenze, 2002)

8. N.Chambers, P.Griffiths, K.Lewis, N.Jenkin, Scotland's Footprint. A resource flow and ecological footprint analysis of Scotland. Report for Viridis (Best Foot Forward Ltd, Oxford, 2004).

10. W. Christaller, Le località centrali della Germania meridionale (FrancoAngeli, Milano, trad.it 1980, 1932)

11. H. E.Daly, Lo stato stazionario (Sansoni, Firenze, 1981)

12. J. de Vries, European Urbanization 1500-1899 (Harvard University Press, Cambridge mass, 1984)

13. J. Diamond, Collasso (Ed. Einaudi, Torino, 2005)

14. P.R. Ehrlich, J. Holdren, The Impact of Population Growth (Science, 171, 1971)

15. F.Ferlaino, Cities and Sustainability: Environmental Urban Curve and Global-scale Territorial Scenarios (Chinese Journal of Regional Science, 4, 5, 2012).

16. Ferlaino F. e Tiezzi E. (a cura), Analisi emergetica della sostenibilità ambientale della Regione Piemonte e del Comune di Torino (IRES-Piemonte, Torino, 2001).

16. N. Georgescu-Roegen, The Entropy Law and the Economic Process (Harvard University Press, Cambridge Mass, 1971)

17. K.G. Høyer, E. Golden, Househol Consumption and Ecologica Footprint in Norway -Does Urban Form Matter? (Journal of Consumer Policy, 26, 2003).

18. M. Kuhndt, Teoria e pratica del delinking del 'benessere' dall' 'uso della natura': Material Flow Accounting (MFA), Material Input per Service Unit (MIPS), Resource Efficiency Accounting (REA), in: F.Ferlaino (a cura), La sostenibilità ambientale del territorio. Teorie e metodi (Utet Libreria, Torino, 2005)

19. S. Latouche, La scommessa della decrescita (Feltrinelli, Milano, 2007)

20. W. Launhardt, Il fondamento matematico dell'economia politica, in: Bagiotti T. (a cura) Marginalisti matematici (UTET, Torino, trad. 1975,1885)

21 A. Maddison Historical Statistics of the World Economy: 1-2008 in: www.ggdc.net/ maddison/Historical.../horizontal-file 02-2010.xls (2010)

22. H. Maturana, F. Varela, Autopoiesi e cognizione. La realizzazione del vivente (Marsilio, Padova, 1985)

23. M. Mazzanti R. Zoboli, Waste indicators, Economic Drivers and Environmental Efficiency: Perspectives ano Delinking and Empirical Evidence for Europe (Quaderno deit, 12,200, Università di Ferrara, 2005)

24. D.H. Meadows et al., I limiti dello sviluppo: Rapporto del System Dynamics Group Massachussets Institute of Technology (MIT) per il progetto del Club di Roma sui dilemmi dell'umanita (Mondadori, Milano, 1974).

25. H.J. Morowitz, Energy Flow in Biology (Ox Bow Press, Woodbridge, 1979)

26. H. T. Odum, Un'analisi basata su 'emergy' ed 'emdollari, in F.Ferlaino (a cura), La sostenibilità ambientale del territorio. Teorie e metodi (Utet Libreria, Torino, 2005)

27. OECD, Monitoring the World Economy 1820-1992 (OECD, Paris, 1995)

28. OECD, The World Economy: A Millennial Perspective (OECD Development Centre, Paris, 2001) 
29. OECD, Indicators to measure decoupling of environmental pressure from economic growth (OECD, Paris, 2002).

30. OECD, The World Economy: Historical Statistics (OECD Development Centre, Paris, 2003)

31. J. Pacholsky, The Ecological Footprint of Berlin (Germany) for the Year 2000 (Stirling University, Scotland, 2000)

32. T. Parsons, Il sistema sociale (Edizioni di Comunità, Milano,trad.1965, 1951)

33. G. Pauli, Blue economy. 10 anni. 100 innovazioni. 100 milioni di posti di lavoro (Ed. Ambiente, Milano, 2010)

34. I.Prigogine, P.M.Allen, R.Herman, La Nuova Alleanza. Uomo e natura in una scienza unificata (Longanesi, Milano, 1979)

35. K. T.Rosen, M. Resnick, The size distribution of cities: An examination of the Pareto law and primacy (Journal of Urban Economics, 8, 2, 1980)

36. R. Thom, Modelli matematici della morfogenesi (Einaudi, Torino,1985)

37. E.Tiezzi, N. Marchettini, Che cos'è lo sviluppo sostenibile? Le basi scientifiche della sostenibilità e $i$ guasti del pensiero unico (Donzelli, Roma, 1999)

38. UN, Population Division of the Department of Economic and Social Affairs of the United Nations Secretariat (World Population Prospects: The 2008 Revision, http://esa.un.org/unpp, 2009)

39. E. U.von Weizsacker, A. B.Lovins, L. H.Lovins, Fattore 4 : come ridurre l'impatto ambientale moltiplicando per quattro l'efficienza della produzione (Edizioni Ambiente, Milano, 1998)

40. WWF, Living Planet Report. Biodiversity, biocapacity and development, (http://awsassets.panda.org/downloads/lpr2010. pdf, 2010)

41. http://esa.un.org/unup/index.asp

42. http://www.footprintnetwork.org/it/index.php/gfn/page/earth overshoot day/

43. https:/www.cia.gov/library/publications/the-world-factbook/rankorder/rankorderguide.html 